\title{
The Relationship of Imquiry to Public Policy
}

\author{
Wayne Sailor and Matthew Stowe \\ University of Kansas
}

In western democracies, public policy has traditionally been informed by inquiry. Examples of this dependent relationship abound in public health and in education. When evidence of deleterious effects on health emerged from research on cigarette smoking, laws were passed to regulate and restrict the tobacco industry. When evidence from systematic inquiry revealed that persons with extensive social and academic support needs could significantly benefit from public education, public policy responded with passage of the Education of the Handicapped Act amendments of 1974. Valuesdriven questions of social importance arise; research is undertaken to extend knowledge that bears on the questions; and resultant evidence from research informs public policy to deal with the questions of interest.

Recently, the nature of the relationship of policy and inquiry has undergone a dramatic and important shift. With passage of No Child Left Behind (NCLB) and accompanying educational legislation at the federal level, policy has begun to not only inform inquiry, but also to restrict it. NCLB has written the process by which inquiry into the education of America's children should occur directly into law and has thus made inquiry itself a matter of policy. In this brief essay, we examine the nature of inquiry and how it has evolved in American culture. We next briefly examine the issue of "evidence" and the importance of how it is defined, both for inquiry and for its application in public policy. From this discussion, we consider the role of policy in inquiry and the implications of altering the traditional relationship of policy to inquiry.

\section{Inquiry}

Here we are concerned with knowledge. How do we know what we think we know? How can we separate what is true from what is false? What are the premises or assumptions that underlie such a task? What are the rules that must be agreed upon to undertake these inquiries? And how do we apply the fruits of our quest for knowledge in the service of our society (if indeed that is our purpose)?

Address all correspondence and requests for reprints to Wayne Sailor, University of Kansas, 1200 Sunnyside, Haworth Hall rm. 3136, Lawrence, KS 66045-7534. E-mail: wsailor@ ku.edu
Inquiry is a values-driven process. In the time of Plato, pursuit of knowledge was its own reward. Inquiry was the pathway to divinity. The American culture of inquiry is tempered by pragmatism (i.e., Peirce, 1934; James, 1975; Dewey, 1976). In America, inquiry rests on an assumption of the benefits of knowledge in the service of society. We seek knowledge to make life better. More than a search for facts (truth), we inquire to discover what works in advancing this broader agenda. The values of pragmatism thus, in large part, guide inquiry in the American cultural tradition (Antonio, 1989).

While values guide why we pursue systematic inquiry, how we inquire is a matter of epistemology. Rules for how we go about systematically acquiring knowledge in the service of American society are anchored in basic philosophical assumptions concerning the nature of what we take to be "reality" and our respective position in relationship to it. American inquiry responds to two quite disparate modern epistemologies.

The first of these, constructivism, is anchored in the German philosophical tradition of subjectivism. Reality can only be understood and described through interpretation and is thus subject to social construction. What is known, as opposed to conjecture, is a matter of social consensus at any point in time. So-called "qualitative" research methods are consistent with this epistemology. In America, the disciplines of sociology and anthropology, together with the profession of social work, are systems of knowledge built in large part with qualitative investigations.

The second epistemology is positivism, which has its roots in the philosophical tradition of British empiricism. Positivists maintain that social and personal phenomena constitute an external reality that can be objectified and measured. So-called "quantitative" (empirical-experimental) research methods derive from positivism. Medicine and education as professions, together with biology and psychology as the principal disciplines that inform them, have been largely guided by positivism in generating their systems of knowledge.

These two dominant epistemologies in American systems of inquiry are not good bedfellows, and have frequently been in conflict with one another (Driver-Linn, 2003; Gieryn, 1999; Sailor \& Paul, in press). As Skrtic 
(1995) has pointed out, Dewey's notion of progressive education as the path to American pragmatic values of democracy, justice, freedom, and equality evolved from pragmatism as a way to steer a course between the disparate European epistemologies.

The term "science" has emerged in recent usage as if it was itself an epistemology, and has become regarded by many as the source of knowledge and truth. While many believe science has its origins as a descriptive term in antiquity, it actually emerged in general usage from a meeting of the British Association in the 19th century (Scriven, 1964; Sailor \& Paul, in press). The term came to be identified with Newtonian physics in Britain and with positivist methods generally in America. When policy-makers begin to equate "science" and "scientific investigation" with the ultimate in pursuit of knowledge, they move away from the pragmatic reconciliation of disparate forms of inquiry that has been a hallmark of American research for over a century.

\section{Evidence}

The above discussion might be of academic interest were it not for its implications for the application of knowledge. In other words, if evidence generated in accordance with only one epistemology is allowable for the purpose of informing professional practice, while evidence generated from another standpoint is not, then policy moves to restrict not only what can be known, but also what can be done with presumed knowledge. As Giangreco and Taylor (2003) point out in this issue, the NCLB legislation not only mandates scientifically based research, but also goes on to specify that the term applies only to investigative methods anchored in a positivist tradition.

A modern parable illustrates the problem. A man is discovered searching for his car keys between where he parked his car on the street and his house. When asked why he is confining his search to a small area some distance from where his car is parked, he replies: "Well, obviously it is because there is a lamp post here. It is dark over where my car is parked." Are we to search only for knowledge that can be gained through application of a particular subset of research methods in the service of educating America's children? Are we to address only those questions that lend themselves to randomized clinical trial designs?

The relationship of evidence to inquiry is analogous to the issue of the relationship in pragmatism between form and function. Research methods are, after all, nothing more than procedures put into place to build confidence in the veracity of evidence developed from inquiry. Without evidentiary rules (i.e., methodology), as any magician will attest, it is simply too easy to represent fiction as fact and to fool well intentioned people. The recent discovery, for example, of a sar- cophagus thought to have held the remains of James, brother of Jesus Christ, turned out to be a hoax. A successful hoax is really a failure of rigor in methodology. When more rigorous methods are applied, hoaxes can be revealed, and what was tentatively accepted as truth is relegated to fiction.

As Denzin and Lincoln (1994) and Miles and Huberman (1994) have illustrated, evidence gathered with methods derived from the constructivist epistemology suffers the same constraints on veracity as does evidence generated with empirical methods. Rigorous methodological "controls" have become as much a characteristic of qualitative methods as they have in "scientific" methods.

Values guide what questions we address (inquiry). Epistemologies (rules for knowing) guide how we address the questions. It can be argued that America has evolved into a highly successful society and has become the world's superpower precisely because of its utilitarian pursuit of knowledge through pragmatism (Rorty, 1991). Sanctioning one form of evidence over another in public policy removes us from that tradition. Perhaps there are good reasons to do so, but such a step should not be taken lightly in the absence of much reasoned discourse.

Within a pragmatic tradition, a question for research often implies a function. One of our democratic values is inclusion (i.e., Skrtic \& Sailor, 1996). A reasonable question might be, for example, what adaptations are needed in a kindergarten curriculum to include a child with autism such that all of the children achieve positive outcomes? A program of research can be constructed to address this question. The methodologies selected will have forms that are best suited to the function (inclusion outcomes) implied by the question. Under NCLB, however, we now have a disconnect between form and function. Certain "forms" have been effectively removed from the realm of educational research. A randomized clinical trial design (the "gold standard" of Shavelson \& Towne, 2002; Spooner \& Browder, 2003 ) is poorly matched to the above question of interest. A rigorous "qualitative" investigation of successful inclusive kindergarten examples might provide a good match of form and function, but such a match would now seem to be seriously constrained, if not ruled out, by newly crafted public policy.

Obviously, a massive disconnect between form and function in the manner in which we generate and validate new knowledge in public education can be expected to have significant implications for how American children are educated, and thus for the very future of the nation. One can easily imagine, for example, the research community responding to this shift in policy governing inquiry by selecting only those questions to be addressed on the basis of goodness of fit between function and allowable form. In education, will children who present research questions relevant to low inci- 
dence occurrence in the general population (i.e., autism) continue to reasonably expect answers? Or will the research community gravitate toward the "gold standard"?

\section{Evidence and Public Policy}

Pragmatism has been the guiding principle behind policy's regulation of professional practice because legislators, agency personnel, and judges have long recognized that professionals are the experts qualified to determine what is and is not acceptable practice in their fields. Thus, policy approaches to regulating research have traditionally focused on such things as accreditation and licensure requirements developed in cooperation with professional organizations. Policy-makers have generally deferred to professional judgments with regard to the choice of specific practice methods, and courtroom determinations of scientific merit are made on a case-by-case basis to evaluate the reliability of the methodology for the specific purpose to which it is applied based on standards outlined by the profession.

Historically, the law has taken a more active role in proscribing the methods through which professionals practice their trade in only two situations: (a) when the judgment of experts is likely to be tainted by bias, such as in regulation of corporate practices or (b) when the state of the art has sufficiently developed and is sufficiently supported by research to memorialize a particular practice in policy. Even in these situations, the use of standards and methods of accountability usually provide adequate protection against bias, ensure outcomes, and still allow professional flexibility to seek new and better methods to achieve the desired policy outcomes.

Neither of these usual suspects seems to justify the specific limitations on methodologies for educational practice under the NCLB or for educational research under the newly created Institute for Educational Sciences. Instead, these policies seem to indicate that there is a new, or at least rarely used historically, third exception to professional deference based on the perception that failure to achieve policy goals, in this case to improve educational outcomes, is due to widespread professional failure to use best practice research methodologies. In other words, there is a perception that failure to achieve educational improvements is due, at least in part, to the failure of research to inform policy and practice to achieve better educational outcomes. Furthermore, the use of invalid, or at least less valid, methods of inquiry is seen as the cause of the failure to inform education policy and practice.

Thus, the movement to reform educational research is based on two causal assumptions: (a) that failure to use "gold standard" research methods has undermined efforts to inform educational policy and practice and (b) that this failure in turn is the reason for a lack of improvement in educational outcomes. Ironically, nei- ther of these assumptions is adequately supported by research applying any standard, "gold" or otherwise. Educational research has used both qualitative and quantitative methods, experimental and nonexperimental designs, to varying degrees and with varying levels of rigor. If a failure to inform educational policy and practice has occurred, shouldn't all of these methods share responsibility? Or more likely, doesn't it suggest that the problem is unrelated to the use of any particular methodology?

Another assumption of the NCLB and Institute for Educational Sciences is that the "gold standard" for research in pharmacology and the medical community, randomized clinical trials, should also be the gold standard for educational research. This assumption seems particularly vulnerable to challenge, considering the differences between medical and educational research. Even in medical research areas, such as pharmacological research, randomized clinical trials (RCTs) are only one of several research methodologies used before putting a drug on the market. RCTs are generally only approved after sufficient in vitro and in vivo research establishes the "mechanism of action" for the proposed drug to provide a strong foundation and justification for the risks and costs associated with RCTs. The role of the "gold standard" in medical research, as the final step in a line of research to develop a medical intervention, is undoubtedly vital and irreplaceable. Yet RCTs seem to have achieved an almost legendary status that reaches beyond the actual strengths and limitations of the methodology and threatens to transform it into the research equivalent of a miracle drug or silver bullet. Before educational research policy goes further in its love affair with the medical model for research, policy-makers should take the time to fully understand why randomized clinical trials have been so successful in medical research.

One of the reasons randomized clinical trials have become the gold standard in medical research is because the goals of the research lend themselves well to the use of RCTs, or in other words, because form fits function. Sampling criteria can be easily used to ensure that all participants are members of the population being studied based on biological conditions. Rarely are there problems with recruitment of a sufficient number of participants; naturally, most people who have a disease want to get better or have their suffering alleviated. External factors that might affect the variables being studied, a real challenge in educational research, are fairly easy to isolate and control in the relatively closed system of the human body.

When RCTs have not been appropriate or even possible, as with the development of some orphan drugs (for which 200,000 people or less have a need), the Food and Drug Administration (FDA) has found it necessary to rely on other research designs to support approval of the drug (Haffner, Whitley, \& Moses, 
2002). One example involved the investigation of pegademase for the treatment of severe combined immunodeficiency (SCID). Because of the rarity of SCID, the drug trial involved only six participants. It was nevertheless approved as it showed efficacy for all six participants. (Haffner et al., 2002) Other designs that have been used to achieve FDA drug approval include openprotocol, open-label, historical control, and crossover trials (Haffner et al., 2002).

Now, consider education. In education research, numerous interrelated factors effecting learning, including legal, cultural, socioeconomic, biological, interpersonal, and individual factors, create a very complex environment in which to conduct research. Research into special education issues face additional challenges because individuals with disabilities have very individualized needs and strengths and because dual diagnosis and conflicting assessments or classifications of disability are common. If these situations existed for investigation of a medical condition, would RCTs be as commonly used compared with other methodologies? A final difference between medical and educational research is that medical research relies heavily on a much stronger, deeper, and more established literature base formed over almost a century of funding unmatched by that allocated to educational research. Educational research is much more commonly exploratory or descriptive because the literature is too thin or even nonexistent with regard to many of the issues being investigated. Educational research, while perhaps having already cut its teeth, is still in its adolescence compared with the fully matured science of medicine. It needs time and the opportunity to grow.

The true issue in any field of research is not whether a specific methodology is given sufficient emphasis, but whether the chosen methodologies for particular inquiries are appropriate to the questions the research is intended to answer and whether a methodology being applied is using sufficient rigor. Even in the more established field of medical research, "there is considerable evidence that many published reports of randomized-clinical trials (RCTs) are poor or even wrong, despite their clear importance.... Poor methodology and reporting are widespread.... Similar problems afflict other study types" (Altman, 2002, p. 2765).

The NCLB and Institute for Educational Sciences approach to mandating methodologies, from a scientific perspective, is based on unproven and unlikely hypotheses. Policy, like research, achieves the best results when new approaches are based on sound and established doctrine. Yet these new policies ignore the traditional doctrine of deference to the professional opinions of those most familiar with the methodologies.

If policy-makers want to address problems in educational research, perhaps they would do better to look for guidance among the long established standards of inquiry with which they are more familiar, such as those used in U.S. courts or the principles that underlie the statutes themselves. The federal rules of evidence state, "'Relevant evidence' means evidence having any tendency to make the existence of any fact that is of consequence to the determination of the action more probable or less probable than it would be without the evidence" (Cornell Law School, 2003). No methodology is specifically excluded, as they all have value upon which decisions can be made to resolve the issues. In a courtroom, the question of the weight given to the evidence, analogous to the value of the research, is a matter that is properly left to the jury, analogous to determinations in peer-reviewed grant funding and publications.

Two of the core principles of the NCLB are, in theory, accountability and flexibility. Yet rather than providing accountability to ensure that the appropriate and rigorous research has been conducted to sufficiently support the use of a particular educational intervention, the NCLB requires that the intervention be "scientifically valid" as defined by the statute, or in other words, the intervention must be tested in an RCT. Thus, the NCLB sacrifices the flexibility of researchers and those who use that research and still fails to hold schools accountable for using scientifically proven educational interventions because it provides no means for assessing the rigor of the research supporting the intervention. RCTs are just as vulnerable to poor design and rigor as other methodologies, and they must still be appropriate to address the relevant inquiries of the research.

So what should be the role of policy in regulating research? Accreditation, licensing, partnerships with professional organizations, outcome-based accountability requirements, and the creation of professional review panels and boards have served both policy and research well and could do so again if a concerted effort is made to have the form of the research method fit the intended function of a question of importance to education. Policy has an important role to play in directing and even focusing research (inquiry) on social problems. This role is consistent with our pragmatic American tradition. It clearly does not have a role to play within this tradition of restricting or determining how scientists in the service of education ply their craft.

\section{References}

Altman, D. G. (2002). Poor quality medical research: What can journals do? Journal of the American Medical Association, 27, 2765-2767.

Antonio, R. J. (1989). The normative foundations of emancipatory theory: Evolutionary versus pragmatic perspectives. American Journal of Sociology, 94, 721-748.

Cornell Law School. (2003). Federal rules of evidence (Rule 401). Retrieved August 29, 2003, from http://www.law. Cornell.edu/rules/frel.

Denzin, N. K., \& Lincoln, Y. S. (1994). Handbook of qualitative research. Thousand Oaks, CA: Sage.

Dewey, J. (1976). Studies in logical theory. In A. Boydston 
(Ed.). John Dewey: The middle works, 1899-1924 (Vol. 1, pp. 239-375). Carbondale: Southern Illinois University Press. (Original work published in 1903).

Driver-Linn, E., (2003). Where is psychology going? Structural fault lines revealed by psychologists' use of Kuhn. American Psychologist, 58, 269-278.

Giangreco, M. F., \& Taylor, S. J. (2003). "Scientifically based research" and qualitative inquiry. Research and Practice for Persons with Severe Disabilities, 28,

Gieryn, T. F. (1999). Cultural boundaries of science: Credibility on the line. Chicago: University of Chicago Press.

Haffner, M. E., Whitley, J., \& Moses, M. (2002). Two decades of orphan product development. Nature Reviews, 1, 821825.

James, W. (1975). Pragmatism. In F. Burkhardt, F. Bowers, \& I. K. Skrupskelis (Eds.), William James: Pragmatism and the meaning of truth (pp. 1-166). Cambridge, MA: Harvard University Press. (Original work published in 1907).

Miles, M. B., \& Huberman, A. M. (1994). Qualitative data analysis. Thousand Oaks, CA: Sage

Peirce, C. S. (1934). How to make our ideas clear. In C. Hartshorne \& P. Weiss (Eds.), Collected papers of Charles Sanders Pierce (Vol. 5, pp. 257-258). Cambridge, MA: Harvard University Press. (Original work published 1878).

Rorty, R. (1991). Objectivity, relativism, and truth: Philosoph- ical papers (Vol. 1). Cambridge and New York: Cambridge University Press.

Sailor, W., \& Paul, J. (in press)Framing positive behavior support in the ongoing discourse concerning the politics of knowledge. Journal of Positive Behavior Interventions.

Scriven, M. (1964). Views of human nature. In T. W. Wann (Ed.). Behaviorism and phenomenology: Contrasting bases for modern psychology (pp. 163-183). Chicago: University of Chicago Press.

Shavelson, R. J., \& Towne, L. (Eds.) (2002). Scientific research in education. Washington, DC: National Academies Press.

Skrtic, T. M. (Ed.). (1995). Disability and democracy: Reconstructing (special) education for postmodernity. New York: New York Teachers College Press.

Skrtic, T. M., \& Sailor, W. (1996). School-linked services integration: Crisis and opportunity in the transition to postmodern society. Remedial and Special Education, 17, 271-283.

Spooner, F., \& Browder, D. M. (2003). Scientifically based research in education and students with low incidence disabilities. Research and Practice for Persons with Severe Disabilities, 28 ,

Received: July 15,2003

Final Acceptance: August 26, 2003

Editor in Charge: Fred Spooner

This research was supported by a grant from the National Institute on Disability and Rehabilitation Research to the Beach Center on Disability, Grant \#H133B980050. 